\title{
Formation of mesoporous nanocrystalline ceria from cerium nitrate, acetate or acetylacetonate
}

\author{
I. V. Zagaynov $\cdot$ S. V. Kutsev
}

Received: 9 January 2013/Accepted: 4 March 2013/Published online: 15 March 2013

(c) The Author(s) 2013. This article is published with open access at Springerlink.com

\begin{abstract}
Ceria nanopowders with a crystallite size of 5-20 $\mathrm{nm}$ have been prepared by the sol-gel method using cerium (III) nitrate, acetate or acetylacetonate as cerium source. Dimethyloctylamine, monoethanolamine, or tetraethylammonium hydroxide were used as low molecular weight stabilizers. In all cases ceria obtained have a mesoporous structure with pore diameter $3-5 \mathrm{~nm}$. It is shown how the initial salt and stabilizer significantly affect the physical-chemical properties of the obtained ceria powders. Also the temperature of $\mathrm{CO}$ full conversion was demonstrated not to be dependent on particle size, surface area, or pore size.
\end{abstract}

Keywords Ceria $\cdot$ Nanocrystalline materials .

Mesopores $\cdot$ Sol-gel $\cdot$ CO oxidation

\section{Introduction}

Nanocrystalline ceria is a unique material having a wide range of applications owing to unusual physical-chemical properties. The special attention to ceria is due to the unique ability of its crystal lattice to reversible redox processes: in a reducing medium it liberates active oxygen with formation of vacancies which can be reversibly healed in an oxidizing medium (Liu et al. 2009). The reason is oxygen donation of ceria caused by partial $\mathrm{Ce}^{4+} / \mathrm{Ce}^{3+}$ reduction on the particle surface (Kockrick et al. 2008). In this context, an item of special urgency is to develop highly efficient scalable

I. V. Zagaynov $(\bowtie) \cdot S$. V. Kutsev

Laboratory of Functional Ceramics, A.A. Baikov Institute of Metallurgy and Materials Science of RAS, Leninskii pr. 49, Moscow, Russia

e-mail: igorscience@gmail.com technologies for the preparation of nanodispersed $\mathrm{CeO}_{2}$ powders with preset micromorphology and controllable particle size distribution to be suitable as precursors for preparation of functional nanocomposites. The most extensively applied techniques are based on synthesis of ceria in organic-inorganic mediums: direct precipitation of ceria from cerium salts (Han et al. 2005; Woodhead 1980; Scholes et al. 2007), synthesis in microemulsions (Sanchez-Dominguez et al. 2009; Sanchez-Dominguez et al. 2010; Patil et al. 2002), sol-gel technique (Laberty-Robert et al. 2006; Thundathil et al. 2004; Xiao et al. 2009; Niederberger and Garnweitner 2006; Gu and Soucek 2007; Gnanam and Rajendran 2011), hydrothermal and hydrothermal-microwave synthesis (Yang et al. 2010; Lawrence et al. 2011; Zhou et al. 2007; Devaraju et al. 2009; Shan et al. 2009; Ivanov et al. 2009), and so on. Nanoscale ceria is very attractive for TWC, SOFC, biological applications, solar cells, UV radiation filters, electrochromic devices, polishing mixtures and abrasives, etc., because of the high mobility of lattice oxygen (Blanco et al. 1999; Milliken et al. 2002; Ivanov et al. 2010; Trovarelli 2002).

In this report, we describe the synthesis of mesoporous ceria by sol-gel method using dimethyloctylamine, monoethanolamine, or tetraethylammonium hydroxide as lowmolecular stabilizers. Only few papers have been published on the use of cerium acetylacetonate, but there was no comparative performance with other precursors in similar conditions (Shaw et al. 2010; Shen and Shaw 2010; Cernea et al. 2006). In this study, a wide range of synthesis conditions have been investigated in order to identify the proper conditions for making ceria with the desired properties. Conditions for making mesoporous ceria powders have also been established. To show the mobility of ceria lattice oxygen the powder samples were tested in the catalytic oxidation of $\mathrm{CO}$. 


\section{Materials and methods}

Synthesis

Cerium (III) nitrate or acetate was dissolved in deionized water (0.05 $\mathrm{M}$ solution) and then after stirring ethanol $\left(\mathrm{H}_{2} \mathrm{O} / \mathrm{C}_{2} \mathrm{H}_{5} \mathrm{OH}=10\right.$ vol. $)$ and a stabilizer such as dimethyloctylamine (DMOA), monoethanolamine (MEA) or tetraethylammonium hydroxide (TEAH) were added. The initial molar ratio of stabilizer/Ce in the reaction mixture was 1 . All procedures were carried out at $80^{\circ} \mathrm{C}$.

Another synthesis was the following: cerium (III) acetylacetonate was dissolved in methanol ( $0.015 \mathrm{M}$ solution) and then a stabilizer was added. After stirring, deionized water $\left(\mathrm{H}_{2} \mathrm{O} / \mathrm{CH}_{3} \mathrm{OH}=0.5 \mathrm{vol}\right.$. $)$ was added to increase the hydrolysis rate (Shaw et al. 2010). The initial molar ratio value of surfactant/Ce in the reaction mixture was 1. All procedures were carried out at $55^{\circ} \mathrm{C}$.

Further, the solvents from sols were evaporated at $90{ }^{\circ} \mathrm{C}$ until the mixture has thickened and a gel was formed. After drying at $100{ }^{\circ} \mathrm{C}$ for $12 \mathrm{~h}$ the xerogels obtained were calcined stepwise at $500{ }^{\circ} \mathrm{C}$ for $4 \mathrm{~h}$.

\section{Characterization}

Powder XRD data were collected at room temperature (DRON$3 \mathrm{M}$, Russia) with $\mathrm{CuK}_{\alpha}$ or $\mathrm{CoK}_{\alpha}$ radiation. Particle size measurements were made by applying the Scherrer equation to the full-width at half maximum (fwhm) of the (111), (200), (220), (311) peaks after accounting for instrumental broadening using germanium as reference (Shelekhov and Sviridova 2000).

Specific surface areas $\left(S_{\mathrm{BET}}\right)$ of the powders were measured by a conventional (BET method) nitrogen sorption method at $77 \mathrm{~K}$ (Tri Star 3000 Micromeritics). Pore-size distributions were calculated from desorption isotherm data using BJH method. Samples were degassed at $120{ }^{\circ} \mathrm{C}$ for $12 \mathrm{~h}$ prior to measurement.

Thermal analysis (TG/DSC) of xerogel was carried out under air flow with Netzsch STA449F3. The samples were heated to $900{ }^{\circ} \mathrm{C}$ at the rate of $5{ }^{\circ} \mathrm{C} / \mathrm{min}$.

SEM was obtained with TescanVEGAII, LEO 1420 scanning electron microscope with accelerating voltage of $20 \mathrm{kV}$.

TEM analyses were conducted on Leo 912AB transmission electron microscope with accelerating voltage of $100 \mathrm{kV}$.

FT-IR spectra were recorded using Thermo Nicolet AVATAR330 FT-IR spectrometer.

The catalytic testing in $\mathrm{CO}$ oxidation was carried out at atmospheric pressure using the continuous-flow U-shaped quartz tube reactor of $6 \mathrm{~mm}$ internal diameter with fixedbed of catalyst. The catalyst sample mass was $0.15 \mathrm{~g}$ and the feed gas passed through the catalytic bed at the total flow rate of $22.6 \mathrm{ml} / \mathrm{min}$. The reaction modeling mixture consisted of 17.7 vol. $\% \mathrm{CO}, 17.7$ vol. $\% \mathrm{O}_{2}$ and $\mathrm{N}_{2}$, the remaining. The reaction temperature was raised stepwise from room temperature till full conversion was obtained. The composition of the outgoing gas stream was determined by gas chromatograph Varian 450GC with TCD and molsive 5A capillary column.

\section{Results and discussion}

Figure 1 shows the XRD pattern of the synthesized ceria nanopowders. All reflexes in the XRD pattern were
Fig. 1 XRD patterns of ceria powders with $\mathrm{CoK}_{\alpha}$ (samples 1-3) or $\mathrm{CuK}_{\alpha}$ (samples 4-9) radiation

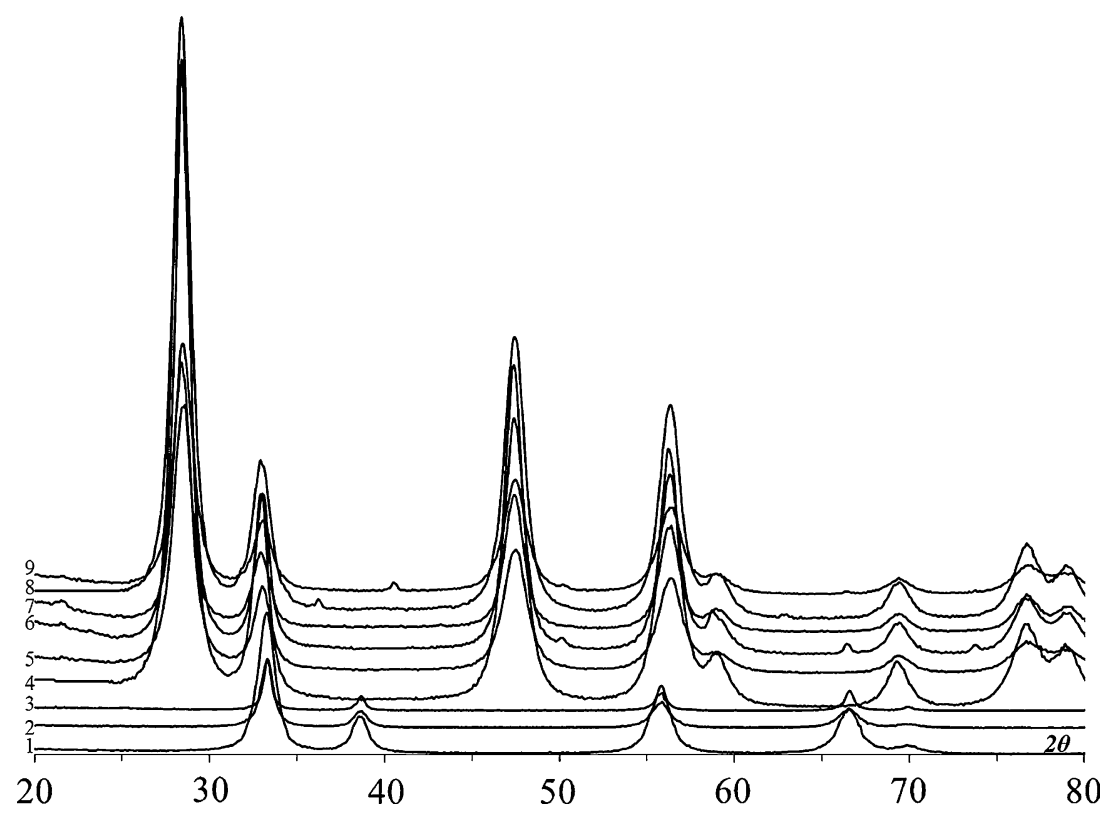


Table 1 Synthesis conditions, crystallites size, and specific surface of ceria powders

\begin{tabular}{llllcll}
\hline No. & Source & Stabilizer & $D_{\text {XRD }}(\mathrm{nm})$ & $S_{\text {BET }}\left(\mathrm{m}^{2} / \mathrm{g}\right)$ & $\begin{array}{l}\text { Proportion of surface area } \\
\text { provided by micropores }(\%)\end{array}$ & $E_{\mathrm{a}}(\mathrm{kJ} / \mathrm{mol})$ \\
\hline 1 & Nitrate & DMOA & 12 & 90.8 & 11.9 & 58.9 \\
2 & & TEAH & 14.5 & 60.6 & 4.3 & 50 \\
3 & & MEA & 21 & 23.4 & 20.3 & 28.7 \\
4 & Acetate & DMOA & 9.1 & 113.1 & 11.6 & 54.2 \\
5 & & TEAH & 8.3 & 129 & 15.3 & 53.8 \\
6 & & MEA & 9.8 & 49.2 & 0 & 47.9 \\
7 & Acetylacetonate & DMOA & 8.9 & 39.3 & 0 & 60 \\
8 & & TEAH & 7.9 & 99.7 & 0 & 71 \\
9 & & MEA & 7.6 & 124.5 & 0 & 36.5 \\
\hline
\end{tabular}

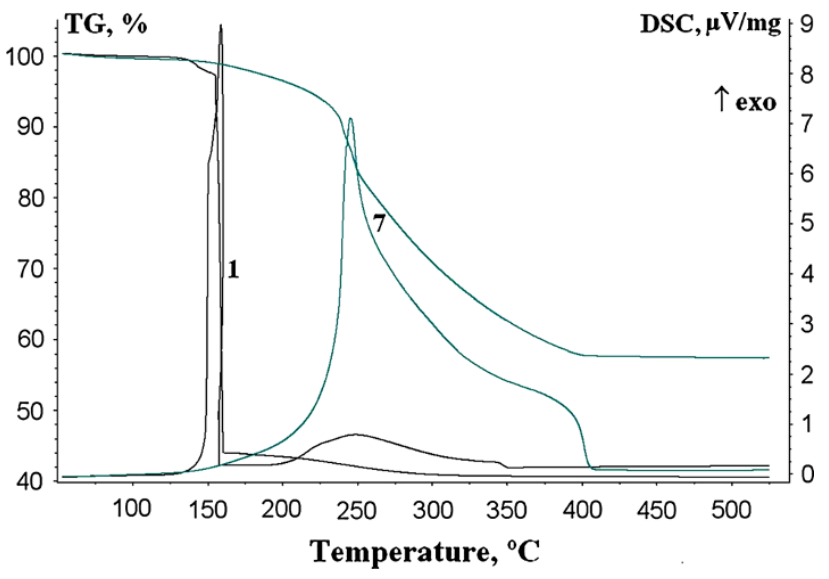

Fig. $2 T G$-DSC curves of xerogel for samples 1 and 7

perfectly indexed as the pure cubic phase (Fm3m, JCPDS34-0394) of $\mathrm{CeO}_{2}$. According to XRD data calculation by Scherer formula the size of ceria crystallites $\left(D_{\mathrm{XRD}}\right)$ was $\leq 20 \mathrm{~nm}$ for all samples (Table 1).

The comparison of ceria dispersibility and specific surface were carried out for powders obtained by use of different stabilizers in sol-gel synthesis at the value of stabilizer/Ce $=1$. When using DMOA or TEAH the crystallite sizes are approximately the same in the series of samples prepared from nitrate or acetate, and they are smaller than with MEA. Perhaps, this is due to the fact that DMOA and TEAH have more large-scale structure of molecules (longer hydrocarbon chain) than MEA, which prevents coagulation of ceria particles in the sol. However, using cerium acetylacetonate the reverse pattern was: the shorter length of hydrocarbon chain, the smaller crystallite size and the higher specific surface. Thus, formative quaternary ammonium in a stabilizer adsorbing on the surface of ceria particles plays a key part in prevention of coagulation, but the quantity is different. In the case of nitrate or acetate stabilization occurs only with low molecular weight stabilizers, and when using acetylacetonate-additionally acetylacetonate group.

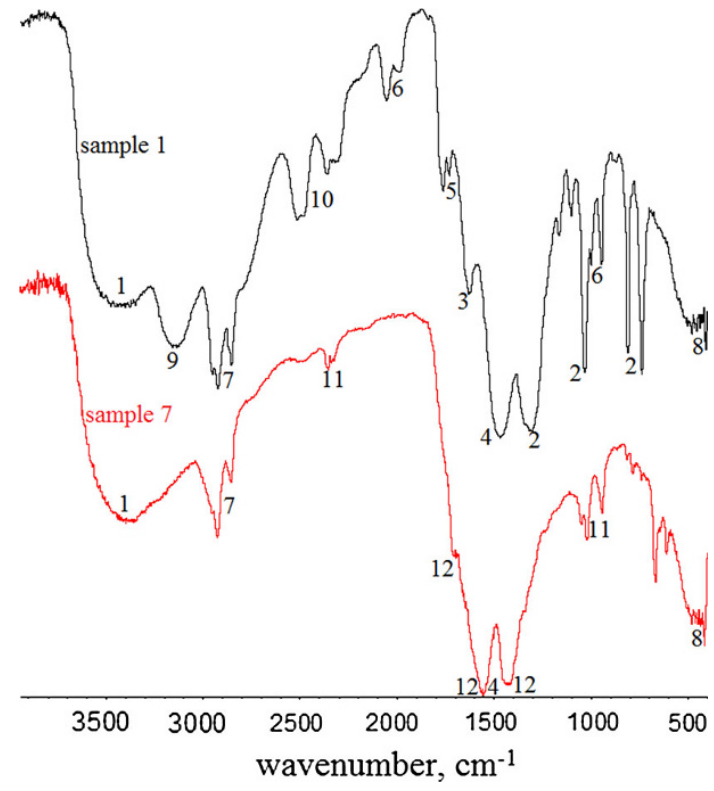

Fig. 3 FT-IR spectra of xerogel for samples 1 and 7

TG-DSC (Fig. 2) confirms the difference in the formation of the final structure of ceria. Physically and chemically bonded water is removed at $150{ }^{\circ} \mathrm{C}$ for sample 1 , then at $200-350{ }^{\circ} \mathrm{C}$ there is a gradual burnout of residual organics. However, for sample 7 removal initiates only at $250{ }^{\circ} \mathrm{C}$, and a complete decomposition occurs only at $415{ }^{\circ} \mathrm{C}$. Apparently, when using acetylacetonate a stable complex was formed; this shifts the temperature of the complete removal of the compounds that are physically and chemically bonded with the intermediate complex of $\mathrm{CeO}_{2}$.

IR spectra (Fig. 3) of both xerogels exhibit absorption bands at $3,400 \mathrm{~cm}^{-1}$ (position 1), attributed to the stretching mode of water; $2,800-2,900 \mathrm{~cm}^{-1}$ (peaks 7) is $\mathrm{C}-\mathrm{H}$ stretching peaks of DMOA; the $\mathrm{Ce}-\mathrm{O}$ band (peaks 8) till $500 \mathrm{~cm}^{-1}$ - the vibration of $\mathrm{CeO}_{2}$. The sample 1 has adsorbed nitrate ions (peaks 2), hydroxyl ion (position 3), carbonate ion (peak 4), acetate ion (peak 5), ethanol (positions 6). Peak 9 may be correspond to $\mathrm{N}=\mathrm{O}$ overtone 


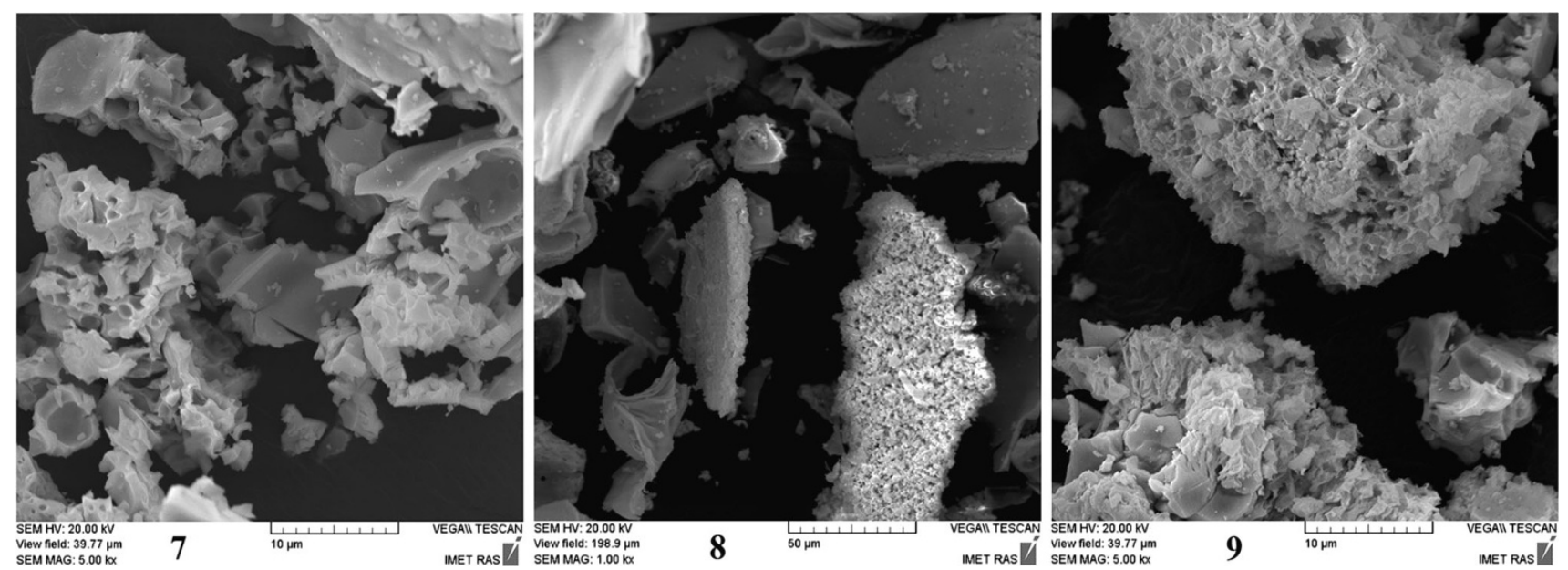

Fig. 4 SEM microphotos of ceria samples 7, 8, 9
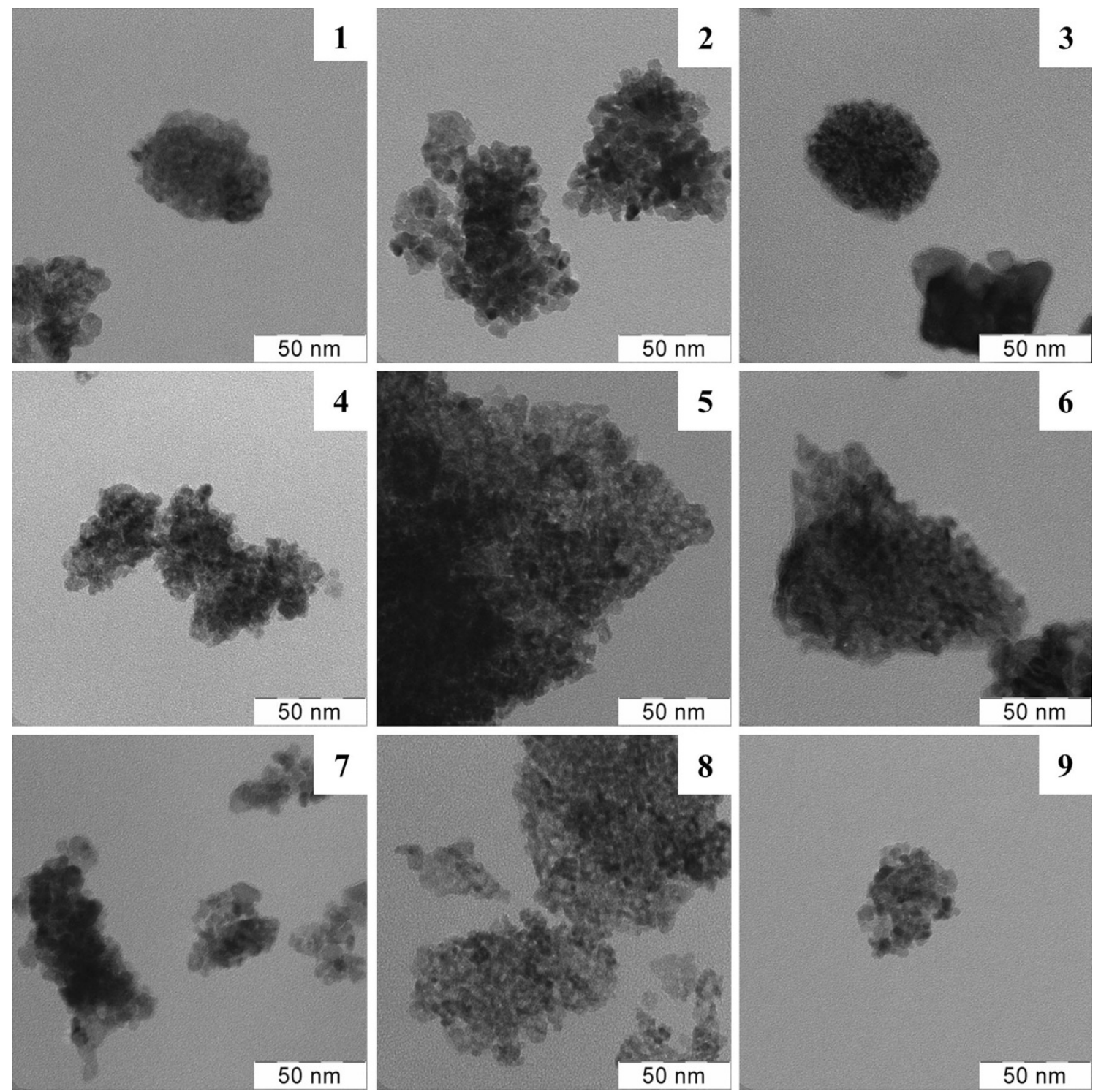

Fig. 5 TEM microphotos of obtained ceria 
in nitrate ion or $\mathrm{NH}_{4}{ }^{+}$. The xerogel has a residual content of DMOA and ethanol as well as carbonate and acetate groups resulting from oxidation of ethanol, they are on the surface of ceria. But peaks 10 were not identified. The sample 7 has residual DMOA (peaks 7) and methanol (peaks 11); and acetylacetone group (positions 12), as well as its possible the presence of carbonate group (peak 4). So, in addition to ceria the xerogel 1 has residual cerium hydroxide and adsorbed nitrate, carbonate, and acetate ions, but xerogel 7 has adsorbed acetylacetonate and carbonate ions; the structure of both xerogels contains alcohol and DMOA.

For the samples obtained from the acetylacetonate, as an example, clearly visible difference is in morphology using various stabilizers (Fig. 4). Sample 7 has nonporous monolithic structure. Sample 9 has a more open porous foamed structure. The morphology of sample 8 is similar to the structure of "cookies", and we can see the individual aggregates and secondary porous space between them.

The aggregates of $\mathrm{CeO}_{2}$ particles are shown on the TEM images (Fig. 5). No differences in the morphology of the samples obtained under different conditions are observed. Particles size is $3-25 \mathrm{~nm}$ with main share falling on $5-10 \mathrm{~nm}$. The particles have spherical shape. Among the series of samples submitted, samples 4-6 obtained from cerium acetate should be noted, which had rodlike particles (not shown here), or the nucleation of such particles in the form of chains of close spherical particles, but their proportion was no more than 1-2\%. So it confirms oriented attachment growth of ceria particles, shown previously only in variations of the hydrothermal method (Ivanov et al. 2010).

All samples have type IV adsorption curve with a hysteresis loop (Fig. 6), indicating the presence of mesopores in the systems. Though samples 1, 4, and 7 have mixed $\mathrm{H} 2$ and $\mathrm{H} 3$-shaped hysteresis loops, implying the presence of cylindrical and slit-shaped pores. Samples 4 and 7 have mostly cylindrical pores, but sample 1 has largely slit pores, that it is observed in nonrigid aggregates of plate like particles giving rise to slit-shaped pores.

Samples have mesopores (Fig. 7) that fit into the size of 3-5 nm, the pore-size distribution curves are very narrow. The only exception is sample 1 , which has a broader pore-size distribution, and the sample 2, which has a size of $2 \mathrm{~nm}$. Acetylacetonate group influences the pore size (it acts as a gelling agent and additional stabilizer for $\mathrm{CeO}_{2}$ particles in sol/gel), which narrows the pore-size distribution (Zagaynov et al. 2012; Trusova et al. 2012).

Figure 8 shows the catalytic activity of ceria powders in $\mathrm{CO}$ oxidation at $\mathrm{CO} / \mathrm{O}_{2}=1$. It is shown that all curves have s-type profile. Also it has three regions of full conversion: (1)

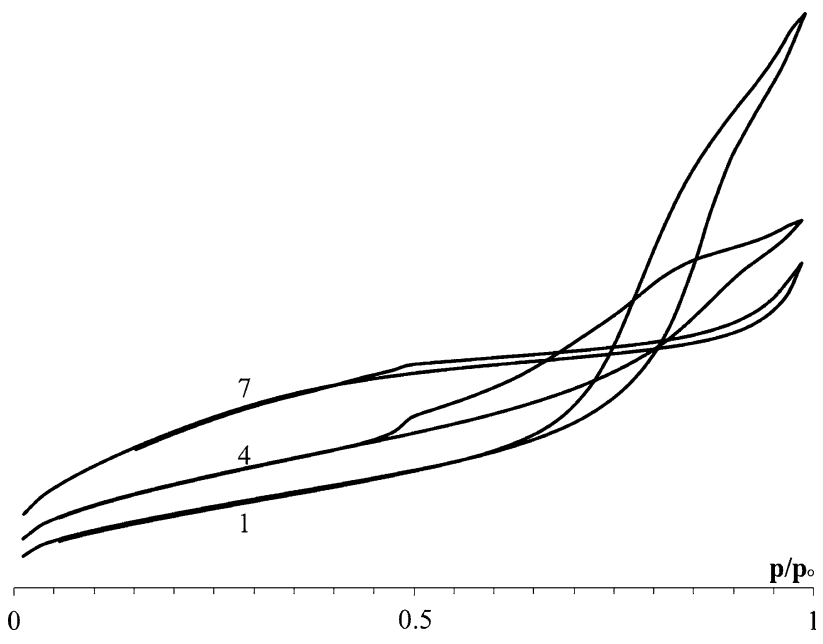

Fig. $6 \mathrm{~N}_{2}$ adsorption/desorption isotherms for samples 1, 4, and 7

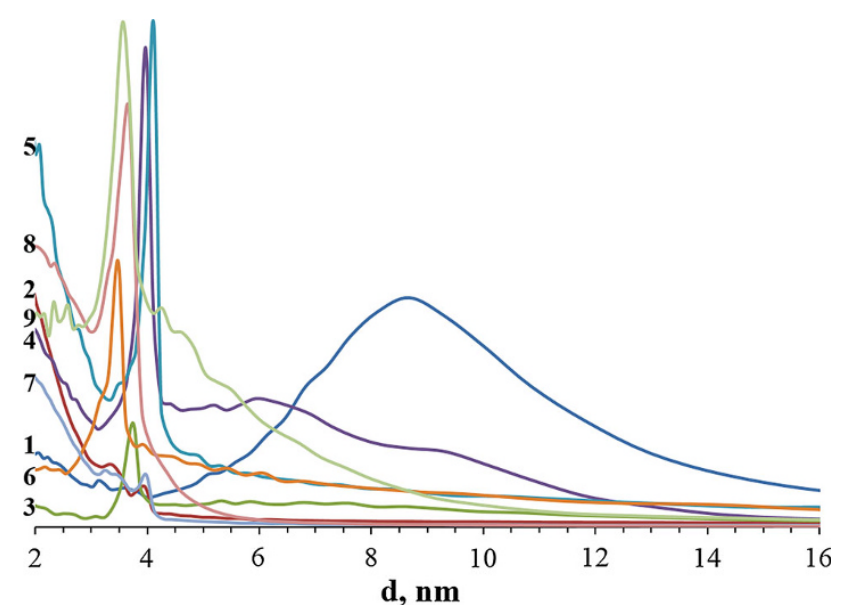

Fig. 7 Pore-size distributions of $\mathrm{CeO}_{2}$ powders

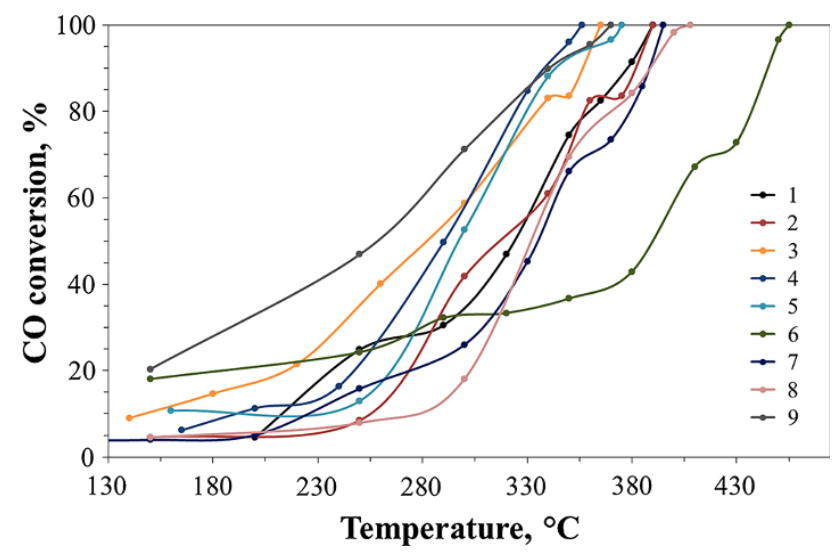

Fig. 8 Catalytic activity of $\mathrm{CeO}_{2}$ powders

samples 4, 3, 9, and 5; (2) samples 1, 2, 7, 8; (3) sample 6 . The activation energy $\left(E_{\mathrm{a}}\right)$ of samples is given in Table 1 . $E_{\mathrm{a}}$ was calculated using the following equation: 
$k=\frac{V}{m / \rho} \ln \left(\frac{1}{1-x}\right), k=k_{o} \mathrm{e}^{\frac{-E_{a}}{R T}}$,

where $V$, linear rate of $\mathrm{CO}(4 \mathrm{ml} / \mathrm{min}) ; m$, catalyst mass $(0.15 \mathrm{~g}) ; \rho$, density of ceria $\left(7.65 \mathrm{~g} / \mathrm{cm}^{3}\right) ; x$, conversion. The rate constant $(k)$ has first order in $\mathrm{CO}$, so $k$ has formal dimension $\mathrm{s}^{-1}$. Thus, the temperature of full conversion cannot be explained by dependence from particle size, surface area, or pore size. It can do by dependence from surface energy, intensity of lattice oxygen mobility, and diffusion in pores.

\section{Conclusion}

Thus, it was shown that the hydrocarbon chain length using the sol-gel synthesis affects the dispersion and specific surface of ceria obtained. Dimethyloctylamine, monoethanolamine, or tetraethylammonium hydroxide were used as low molecular weight surfactants (stabilizers) and they strongly affect the final porosity. In all cases ceria obtained have a mesoporous structure. The effect of acetylacetonate influencing on the pore size also has been demonstrated. It was shown that the temperature of CO's complete conversion is not dependent on particle size, surface area, or pore size.

Open Access This article is distributed under the terms of the Creative Commons Attribution License which permits any use, distribution, and reproduction in any medium, provided the original author(s) and the source are credited.

\section{References}

Blanco G, Calvino JJ, Cauqui MA, Corchado P, López-Cartes C (1999) Nanostructural evolution under reducing conditions of a $\mathrm{Pt} / \mathrm{CeTbOx}$ catalyst: a new alternative system as a TWC component. Chem Mater 11:3610-3619. doi:10.1021/cm $991093 q$

Cernea M, Monnereau O, Llewellyn P, Tortet L, Galassi C (2006) Sol-gel synthesis and characterization of $\mathrm{Ce}$ doped-BaTiO ${ }_{3}$. J Euro Ceram Soc 26:3241-3246. doi:10.1016/j.jeurceramsoc. 2005.09.039

Devaraju MK, Yin S, Sato T (2009) Morphology control of cerium oxide particles synthesized via a supercritical solvothermal method. Appl Mater Interfaces 1:2694-2698. doi:10.1021/am $900574 \mathrm{~m}$

Gnanam S, Rajendran V (2011) Synthesis of $\mathrm{CeO}_{2}$ or $\alpha-\mathrm{Mn}_{2} \mathrm{O}_{3}$ nanoparticles via sol-gel process and their optical properties. J Sol-Gel Sci Technol 58:62-69. doi:10.1007/s 10971-010-2356-9

$\mathrm{Gu}$ H, Soucek MD (2007) Preparation and characterization of monodisperse cerium oxide nanoparticles in hydrocarbon solvents. Chem Mater 19:1103-1110. doi:10.1021/cm061332r

Han WQ, Wu L, Zhu Y (2005) Formation and oxidation state of $\mathrm{CeO}_{2-x}$ nanotubes. J Am Chem Soc 127:12814-12815. doi:10. $1021 / \mathrm{ja} 054533 \mathrm{p}$
Ivanov VK, Polezhaeva OS, Gil' DO, Kopitsa GP, Tret'yakov YuD (2009) Hydrothermal microwave synthesis of nanocrystalline cerium dioxide. Doklady Chem 426:131-133. doi:10.1134/ S0012500809060056

Ivanov VK, Polezhaeva OS, Tret'yakov YuD (2010) Nanocrystalline ceria: synthesis, structure-sensitive properties, and promising applications. Russ J Gen Chem 80:604-617. doi:10.1134/S 1070363210030412

Kockrick E, Schrage C, Grigas A, Geiger D, Kaskel ST (2008) Synthesis and catalytic properties of microemulsion-derived cerium oxide nanoparticles. J Solid State Chem 181:1614-1620. doi:10.1016/j.jssc.2008.04.036

Laberty-Robert C, Long JW, Lucas EM, Pettigrew KA, Stroud RM, Doescher MS, Rolison DR (2006) Sol-gel-derived ceria nanoarchitectures: synthesis, characterization, and electrical properties. Chem Mater 18:50-58. doi:10.1021/cm051385t

Lawrence NJ, Brewer JR, Wang L, Wu TS, Wells-Kingsbury J, Ihrig MM, Wang G, Soo YL, Mei WN, Cheung CL (2011) Defect engineering in cubic cerium oxide nanostructures for catalytic oxidation. Nano Lett 11:2666-2671. doi:10.1021/nl200722z

Liu X, Zhou K, Wang L, Wang B, Li Y (2009) Oxygen vacancy clusters promoting reducibility and activity of ceria nanorods. J Am Chem Soc 131:3140-3141. doi:10.1021/ja808433d

Milliken C, Guruswamy S, Khandkar A (2002) Properties and performance of cation-doped ceria electrolyte materials in solid oxide fuel cell applications. J Am Ceram Soc 85:2479-2486. doi:10.1111/j.1151-2916.2002.tb00484.x

Niederberger M, Garnweitner G (2006) Organic reaction pathways in the nonaqueous synthesis of metal oxide nanoparticles. Chem Eur J 12:7282-7302. doi:10.1002/chem.200600313

Patil S, Kuiry SC, Seal S, Vanfleet R (2002) Synthesis of nanocrystalline ceria particles for high temperature oxidation resistant coating. J Nanopart Res 4:433-438. doi:10.1023/A:10216 96107498

Sanchez-Dominguez M, Boutonnet M, Solans C (2009) A novel approach to metal and metal oxide nanoparticle synthesis: the oil-in-water microemulsion reaction method. J Nanopart Res 11:1823-1829. doi:10.1007/s11051-009-9660-8

Sanchez-Dominguez M, Liotta LF, Di Carlo G, Pantaleo G, Venezia AM, Solans C, Boutonnet M (2010) Synthesis of $\mathrm{CeO}_{2}, \mathrm{ZrO}_{2}$, $\mathrm{Ce}_{0.5} \mathrm{Zr}_{0.5} \mathrm{O}_{2}$, and $\mathrm{TiO}_{2}$ nanoparticles by a novel oil-in-water microemulsion reaction method and their use as catalyst support for CO oxidation. Catal Today 158:35-43. doi:10.1016/j. cattod.2010.05.026

Scholes FH, Hughes AE, Hardin SG, Lynch P, Miller PR (2007) Influence of hydrogen peroxide in the preparation of nanocrystalline ceria. Chem Mater 19:2321-2328. doi:10.1021/cm0626482

Shan W, Dong X, Ma N, Yao S, Feng Z (2009) The synthesis of threedimensional $\mathrm{CeO}_{2}$ and their catalytic activities for $\mathrm{CO}$ oxidation. Catal Lett 131:350-355. doi:10.1007/s10562-009-0069-x

Shaw LL, Shen C, Thomas EL (2010) Synthesis of gadolinia-doped ceria gels and powders from acetylacetonate precursors. J SolGel Sci Technol 53:1-11. doi:10.1007/s10971-009-2043-x

Shelekhov EV, Sviridova TA (2000) Programs for X-ray analysis of polycrystals. Met Sci Heat Treat 42:309. doi:10.1007/BF02 471306

Shen C, Shaw LL (2010) FTIR analysis of the hydrolysis rate in the sol-gel formation of gadolinia-doped ceria with acetylacetonate precursors. J Sol-Gel Sci Technol 53:571-577. doi:10.1007/s 10971-009-2133-9

Thundathil MA, Lai W, Noailles L, Dunn BS, Haile SM (2004) High surface-area ceria aerogel. J Am Ceram Soc 87:1442-1445. doi: 10.1111/j.1551-2916.2004.01442.x

Trovarelli A (2002) Catalysis by ceria and related materials. Imperial College Press, London 
Trusova EA, Vokhmintcev KV, Zagainov IV (2012) Wet-chemistry processing of powdery raw material for high-tech ceramics. Nanoscale Res Lett 7:58. doi:10.1186/1556-276X-7-58

Woodhead JL (1980) US Patent 4231893

Xiao H, Ai Z, Zhang L (2009) Nonaqueous sol-gel synthesized hierarchical $\mathrm{CeO}_{2}$ nanocrystal microspheres as novel adsorbents for wastewater treatment. J Phys Chem C 113:16625-16630. doi:10.1021/jp9050269
Yang Z, Han D, Ma D, Liang H, Liu L, Yang Y (2010) Fabrication of monodisperse $\mathrm{CeO}_{2}$ hollow spheres assembled by nano-octahedra. Cryst Growth Des 10:291-295. doi:10.1021/cg900898r

Zagaynov IV, Trusova EA, Belousov VV (2012) Nanoscale ceria for new functional materials. J Phys Conf Ser 345:012022. doi: 10.1088/1742-6596/345/1/012022

Zhou K, Yang Z, Yang S (2007) Highly reducible $\mathrm{CeO}_{2}$ nanotubes. Chem Mater 19:1215-1217. doi:10.1021/cm062886x 